\title{
Treatment of Multiple Myeloma and Macroglobulinemia Waldenström: A Long-Term Follow-Up Study
}

\author{
Seiju Onodera, Masamichi Ohtaki, Kosure Oikawa, \\ Masatsugu Mikami, Isao Sato, Katsuhisa Ninkawa and \\ TAKashro SUzUKi \\ Second Department of Internal Medicine, Tohoku University \\ School of Medicine, Sendai
}

Onodera, S., Ohtakr, M., OtKawa, K., Mrkam, M., Sato, I., Nirkawa, K. and SUzukI, T. Treatment of Multiple Myeloma and Macroglobulinemia Waldenström: A Long-Term Follow-Up Study. Tohoku J. exp. Med., 1975, 116 (4), 317-325 Fifteen cases of multiple myeloma and 6 cases of macroglobulinemia Waldenström were followed up from 1957 to 1974. As for administration of drugs a low continuous dose regimen was mainly employed instead of a high intermittent dose regimen. $50 \%$ survival time from the onset of the disease was 18 months for multiple myeloma and 25 months for macroglobulinemia Waldenström. 3 cases of multiple myeloma are still living 44 months after the onset of symptoms. Cyclophosphamide and melphalan seem to have contributed much to the prolonged survival of these patients as well as improved supportive care. - multiple myeloma; prolonged survival; cyclophosphamide and melphalan

It had been widely accepted until early 1960 s that multiple myeloma was an uncontrollable disease with pain, pathological fractures, paraplegia, renal failure and death within a few months of diagnosis in spite of irradiation therapy or treatments with agents such as urethane and corticosteroids (Holland et al 1966; Farhangi and Osserman 1973). At present the above view seems to require some correction because of appearance of patients who can survive under fairly good conditions with prolonged survival (Costa et al. 1973).

It is the purpose of this paper to describe our follow-up studies of 21 cases of multiple myeloma and macroglobulinemia Waldenström for the past 15 years, and to analyze the factors which caused the prolongation of survival in these patients.

\section{Materials and Methods}

The cases studied were 15 cases of multiple myeloma and 6 cases of macroglobulinemia Waldenström which were admitted to the Second Department of Internal Medicine, Tohoku University Hosptial from 1957 to 1972.17 cases of these patients are already dead and 3 cases still living. The class and type of M-protein, sex, age and year of disease onset, length of survival, chemotherapeutic agents mainly used and the cause of death in these patients are shown in Table 1.

Diagnosis of multiple myeloma was based on the clinical and laboratory data at the

Received for publication, February 27, 1975. 
TABLE 1. Summary of 21 patients studied

\begin{tabular}{|c|c|c|c|c|c|c|c|}
\hline $\begin{array}{l}\text { Case } \\
\text { No. }\end{array}$ & $\begin{array}{c}\text { Sex } \\
\& \\
\text { Age }\end{array}$ & $\begin{array}{l}\text { Monoclonal } \\
\text { Ig type }\end{array}$ & $\begin{array}{l}\text { Survival } \\
\text { length } \\
\text { (months) }\end{array}$ & $\begin{array}{c}\text { Year of } \\
\text { disease } \\
\text { onset }\end{array}$ & $\begin{array}{c}\text { Chemotherapeutic } \\
\text { agents }\end{array}$ & & $\begin{array}{l}\text { Cause of } \\
\text { death }\end{array}$ \\
\hline 1 & F 50 & & 4 & 1957 & & S. & Heart failure \\
\hline 2 & M 51 & & 15 & 1958 & U. & & Melena \\
\hline 3 & F 65 & & 20 & 1961 & & & Pneumonia \\
\hline 4 & M 64 & & 6 & 1962 & & S. & Heart failure \\
\hline 5 & F 60 & $\operatorname{IgG} \lambda$ & 17 & 1963 & U.C. & S. & Renal failure \\
\hline 6 & M 57 & $\operatorname{IgD} \lambda$ & 14 & 1964 & C. & S. & Pneumonia \\
\hline 7 & F 57 & $\operatorname{IgA} \kappa$ & 13 & 1966 & C. & S. & Shock \\
\hline 8 & M 63 & $\operatorname{Ig} \mathrm{G}_{\kappa}$ & 24 & 1966 & C. & & Unclear \\
\hline 9 & F 59 & $\operatorname{Ig} G_{k}$ & $>60$ & 1970 & C. & S. & Living \\
\hline 10 & M 64 & $\operatorname{IgG\kappa }$ & 41 & 1970 & M.C. & S. & Unclear \\
\hline 11 & M 57 & $\operatorname{IgG} \lambda$ & 42 & 1970 & M.C.V.P. & I.S. & Cachexia \\
\hline 12 & F 50 & $\lambda$ & 36 & 1971 & M. & S. & Renal failure \\
\hline 13 & M 61 & $\kappa$ & $>46$ & 1971 & M. & S. & Living \\
\hline 14 & F 64 & $\lambda$ & $>44$ & 1971 & $\mathrm{M}$ & & Living \\
\hline 15 & F 62 & $\operatorname{Ig} A \lambda$ & 10 & 1972 & & & Shock \\
\hline 16 & M 56 & $\operatorname{Ig}_{\kappa}$ & 19 & 1964 & C. & S. & Renal failure \\
\hline 17 & F 49 & $\operatorname{Ig} M_{\kappa}$ & 36 & 1967 & & S. & Ascites \\
\hline 18 & M 61 & $\operatorname{Ig} \mathrm{M}_{\lambda}$ & 32 & 1967 & C. & $\mathrm{S}$. & Hematemesis \\
\hline 19 & M 59 & $\operatorname{Ig} \mathrm{M}_{\lambda}$ & 60 & 1967 & C. & & Amyloidosis \\
\hline 20 & M 35 & $\operatorname{Ig} \mathrm{M}_{\kappa}$ & 5 & 1972 & V.C. MP. & $\mathrm{S}$. & Cachexia \\
\hline 21 & M 62 & $\operatorname{Ig} \mathrm{M}_{\kappa}$ & 25 & 1972 & Ch. V. & & Pyelonephritis \\
\hline
\end{tabular}

$\mathrm{U} .=$ Urethane $\mathrm{C} .=$ Cyclophosphamide $\mathrm{S} .=$ Corticosteroids $\mathrm{V} .=$ Vinca alkaloids $\mathrm{P} .=$ Procarbazine $\mathrm{I} .=\mathrm{Ir}$ radiation $\mathrm{M} .=$ Melphalan $\mathrm{Ch} .=$ Chlorambucil $\mathrm{MP} .=6 \mathrm{MP}$

TABLE 2. Laboratory and clinical data on 15 cases of multiple myeloma

\begin{tabular}{lcc} 
& Mean & Range \\
\hline Plasma cells in marrow $(\%)$ & 53.5 & $20.8-90.4$ \\
Total serum protein $(\mathrm{g} / \mathbf{1 0 0} \mathrm{ml})$ & 8.9 & $5.1-13.5$ \\
Bence-Jones proteinuria & & $67 \%^{*}$ \\
Osteolytic lesion by X-ray & & $646^{*}$ \\
Bone pain & & $83 \%^{*}$ \\
Paralysis in extremities & & $13 \%^{*}$ \\
Skin tumor & 101 & $13 \% *$ \\
ESR in 1 hour $(\mathrm{mm})$ & 217 & $14-169$ \\
RBC $\left(10^{4} / \mathrm{mm}^{3}\right)$ & 9,065 & $132-492$ \\
WBC $\left(/ \mathrm{mm}^{3}\right)$ & 17.7 & $1,950-44,000$ \\
Platelets $\left(\times 10^{4} / \mathrm{mm}^{3}\right)$ & 30.6 & $1.9-33.6$ \\
Urea-N $(\mathrm{mg} / 100 \mathrm{ml})$ & 9.9 & $8.6-13.6$ \\
Serum Ca $(\mathrm{mg} / 100 \mathrm{ml})$ & & \\
\hline
\end{tabular}

* $\%$ of positive cases

time of admission shown in Table 2. Diagnosis of macroglobulinemia Waldenström was similarly supported by characteristic clinical and laboratory findings (McCallister et al. 1967), and the presence of $\operatorname{IgM} M$-protein and the proliferation of lymphoreticular tissue were two essential requisites for diagnosis.

When indicated, quantitation of immunoglobulins was performed by the antibodyagar plate method as described previously (Mancini et al, 1965; Onodera et al. 1967) and measurement of serum viscosity by the method of Wright and Jenkins (1970).

The followings are the daily doses for each chemotherapeutic agent employed: 


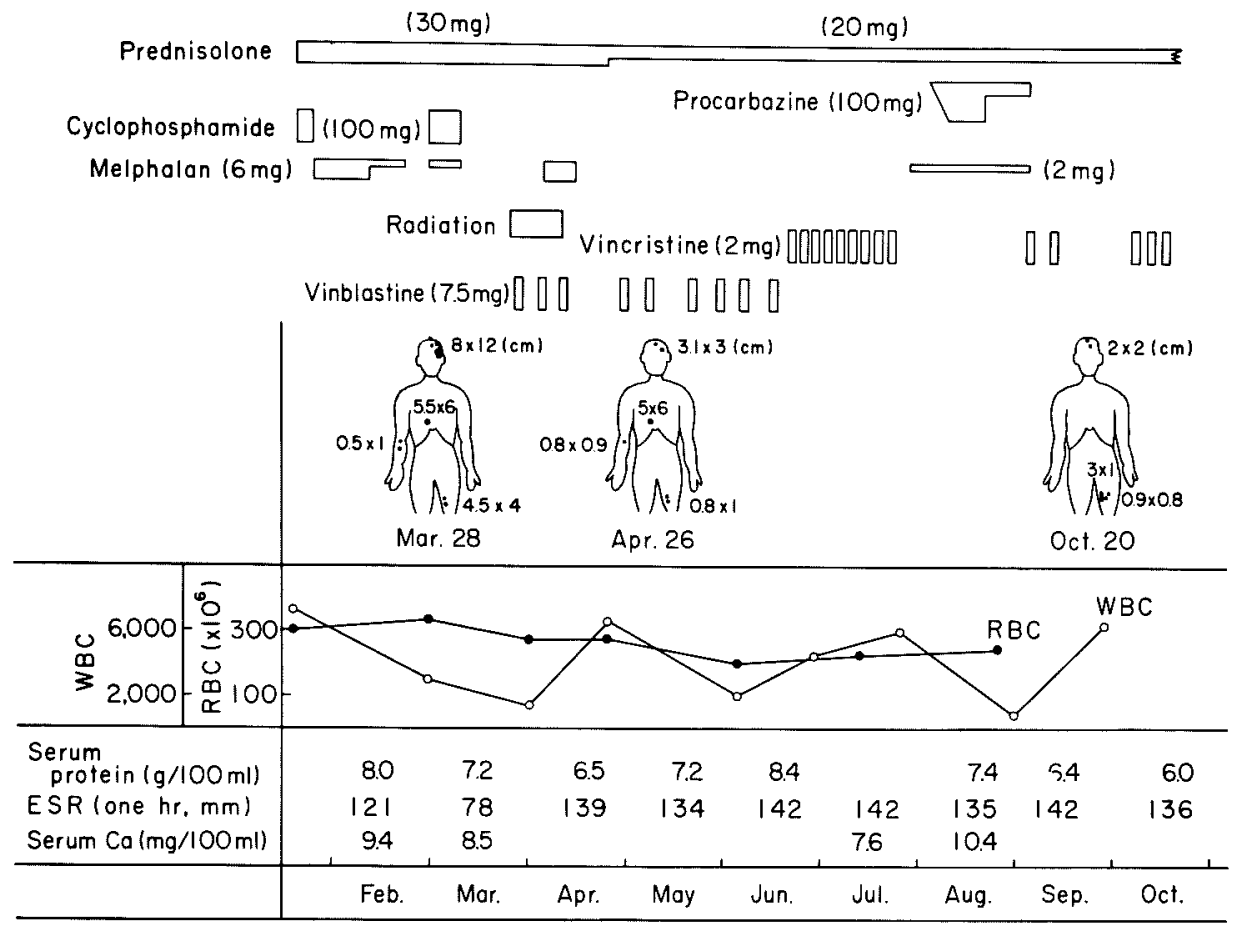

Fig. 1. Clinical course of Case 11.

urethane $2 \mathrm{~g}$, cyclophosphamide $50-150 \mathrm{mg}$, melphalan 2-6 mg, procarbazine $100-150 \mathrm{mg}$; vincristine and vinblastine was given in weekly doses of 1-2 mg and 5-10 $\mathrm{mg}$, respectively. In the majority of the cases only a single agent was administered indefinitely until side effects such as anorexia, nausea, paresthesia in limbs, leukopenia, hepatic disturbance, appeared. When one agent was considered as ineffective after administration for 1-3 months from the points of responding criteria generally employed (Alexanian et al. 1968; Costa et al. 1973), it was switched to another agent. Corticosteroids were administered supplementarily when the above chemotherapeutic agents used seem to have less effect than expected or when they have to be stopped because of side effects. In case 11 of Table 1 various agents were employed, sometimes in combination, for the growing skin tumors as shown in Fig. 1. The summary of this case is as follows:

This case, 57-year-old male, was admitted to Tohoku University Hospital because of general fatigue in August, 1971. Since December 1970, he had begun to complain of fatigability and headache. To clarify the cause of anemia bone marrow aspiration had been performed in a local hospital and the diagnosis of multiple myeloma already established. Subsequently cyclophosphamide and prednisolone had been administered. At the time of transfer to our institution for further treatment the marrow study revealed that plasma cells constituted 60 per cent of the nucleated cells in bone marrow. There was seen a monoclonal peak in $\gamma$ region in cellulose acetate membrane electrophoresis, and an IgG ( $\lambda$ ) M-bow was present in immunoelectrophoresis. The administration of cyclophosphamide was continued. Since his condition improved with this treatment and the plasma cells decreased to 15 per cent in bone marrow, he was discharged on cyclophosphamide.

He was readmitted in January, 1973 because of visual disturbance due to increasing tumors originating in the left orbital area. Physical examination revealed tumors not only at exterior edge of the left orbita, but also on the skin of right forearm and on the back. 
The sizes of tumors are shown in Fig. 1 as well as the course of this second admission. No lymph node enlargement was detected. Lungs were clear and no heart murmurs were audible. The liver and spleen were not palpable. No pedal edema was present.

Laboratory examinations revealed the erythrocyte sedimentation rate $121 \mathrm{~mm}$ in one $\mathrm{hr}$, the red blood cell count 3 million per $\mathrm{mm}^{3}$ and no protein in urine. The total serum protein was $8.0 \mathrm{~g}$ per cent with 21.4 per cent $\gamma$-globulin and the serum calcium $9.4 \mathrm{mEq} / \mathrm{liter}$. The bone marrow aspiration disclosed no increase of plasma cells, but the biopsy of the tumor in the skin showed the histological picture compatible with plasmacytoma.

Since the patient was on prednisolone at the time of this admission its reduced dose was continued. In spite of administration of both cyclophosphamide and melphalan the tumor kept growing. Therefore, two months after this second admission a weekly administration of $7.5 \mathrm{mg}$ vinblastine was started as well as local irradiation of the orbital tumors. After three weeks of this treatment with vinblastine all the tumors on the various parts of the body decreased considerably in size, including the ones which had not received the local irradiation. The tumors began to re-grow soon after vinblastine had to be discontinued because of leukopenia and paresthesia in the extremities. For further trial with vinca alkaloids, $2 \mathrm{mg}$ vincristine was administered this time twice a week, and the tumors decreased again in size. As shown in Fig. 1, even procarbazine was administered with some response. Nevertheless, in spite of such temporary relieves with these various agents his general conditions kept deteriorating and he expired 42 months after his disease onset.

\section{Results}

Fig. 2 represents the length of survival in each case of myeloma patients since disease onset and the total amount of drugs administered during its survival. Cases 9,13 , and 14 are still living, the survival time at present being 62,46 and 44

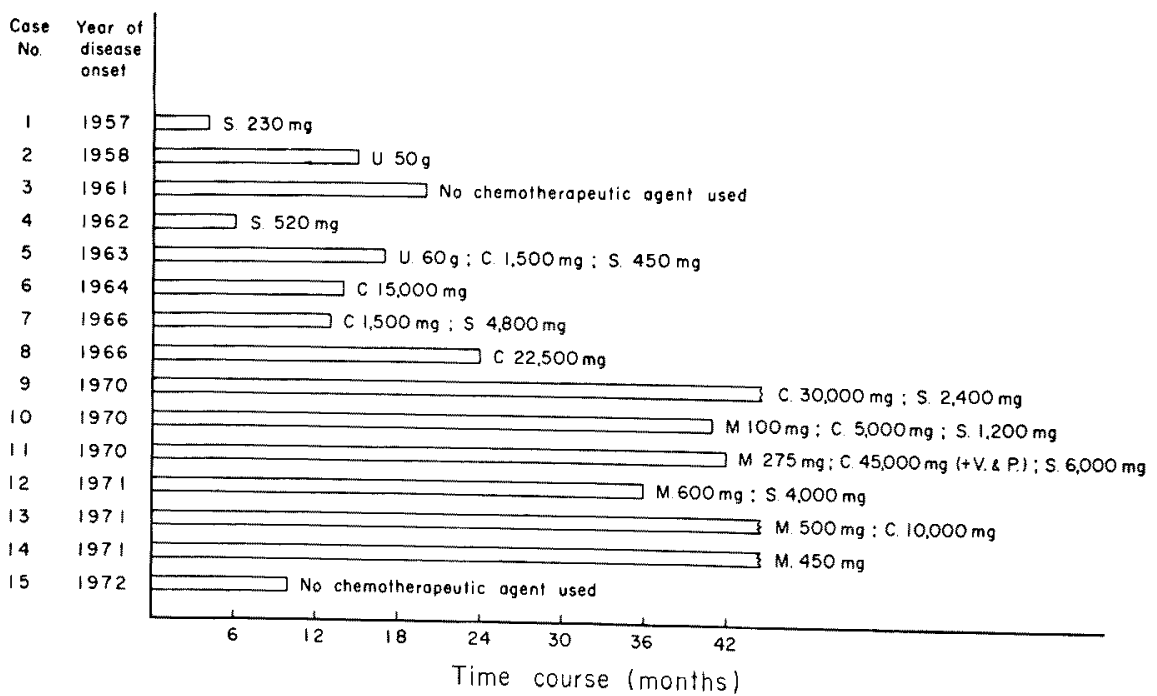

Fig. 2. Length of survival in each case of multiple myeloma and the total amount of drugs administered during its survival.

$\mathrm{S} .=$ Corticosteroids (the doses converted to the corresponding doses of prednisolone)
U. $=$ Urethane
C. = Cyclophosphamide
M. = Melphalan
$\mathrm{V} .=$ Vinca alkaloids

P. $=$ Procarbazine 


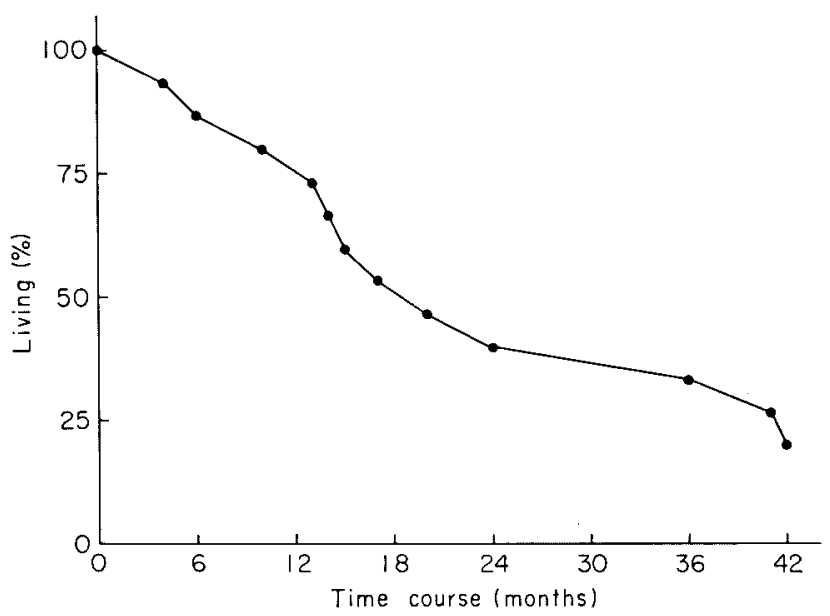

Fig. 3. Survival curve of 15 cases of multiple myeloma calculated from disease (symptom) onset.

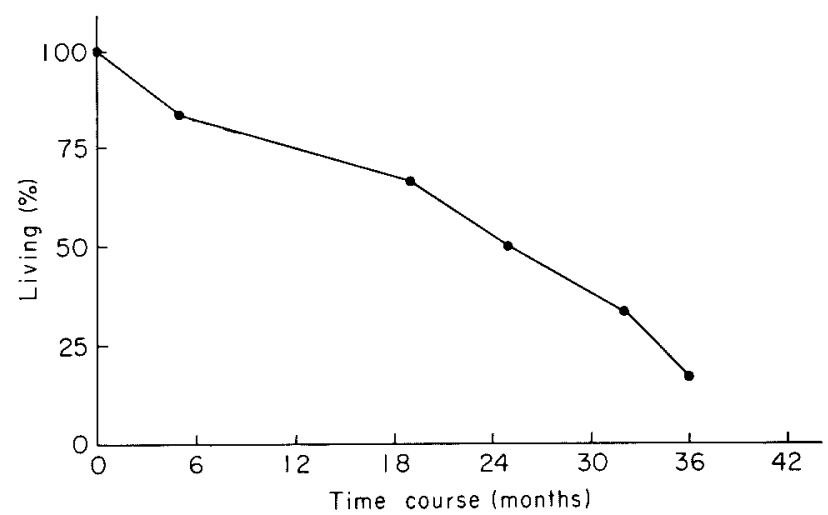

Fig. 4. Survival curve of 6 cases of macroglobulinemia Waldenström calculated from disease (symtom) onset.

months, respectively. Although the survival time of case 15 is short, this case died soon after admission to our institution. Not having received any chemotherapeutic agent for several months before admission, his condition was already grave when transferred for our treatment.

Admitting some exceptions, Fig. 2 shows that the survival of myeloma patient has recently been prolonged, especially after the appearance of cyclophosphamide and melphalan for treatment of this illness.

Fig. 3 represents the survival curve of these 15 cases of multiple myeloma. Duration of survival was calculated from the onset of symptoms. This figure shows that 50 per cent of the cases survived only for 18 months. This seems to be a rather short interval but it must be considered that the cases in 1960 s are included. Three cases are still living 44 months after onset of symptoms. 


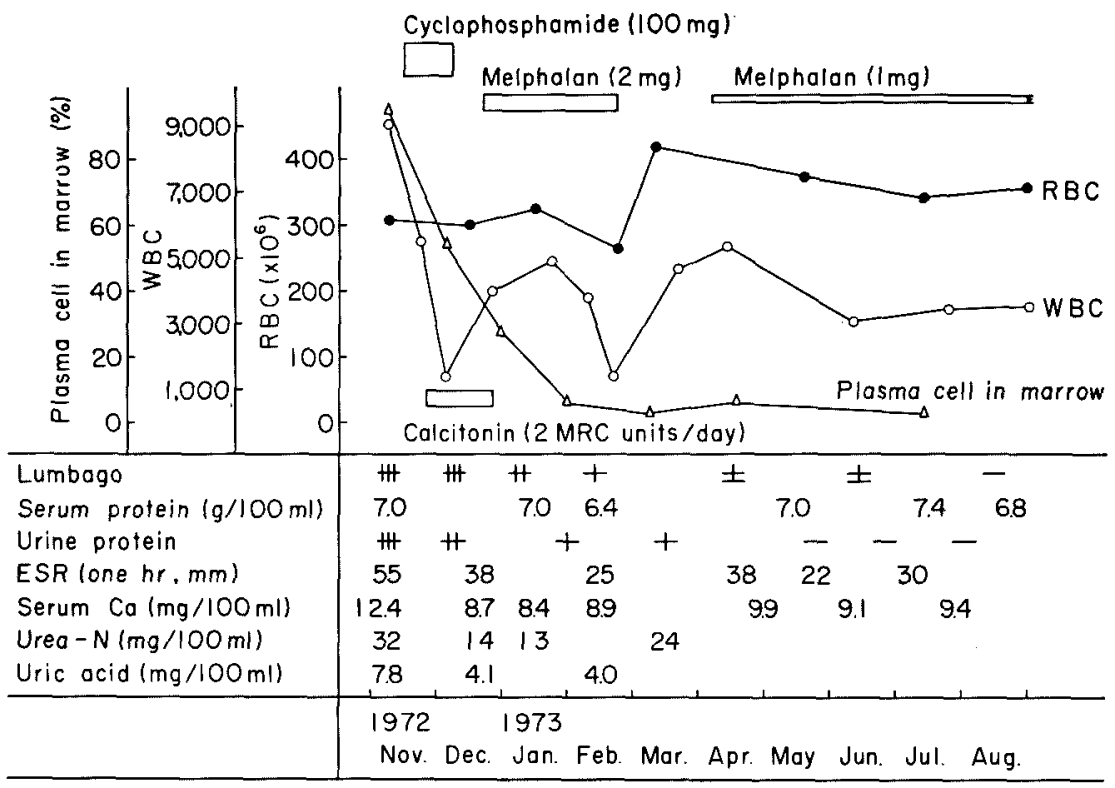

Fig. 5. Part of clinical course of Case 14.

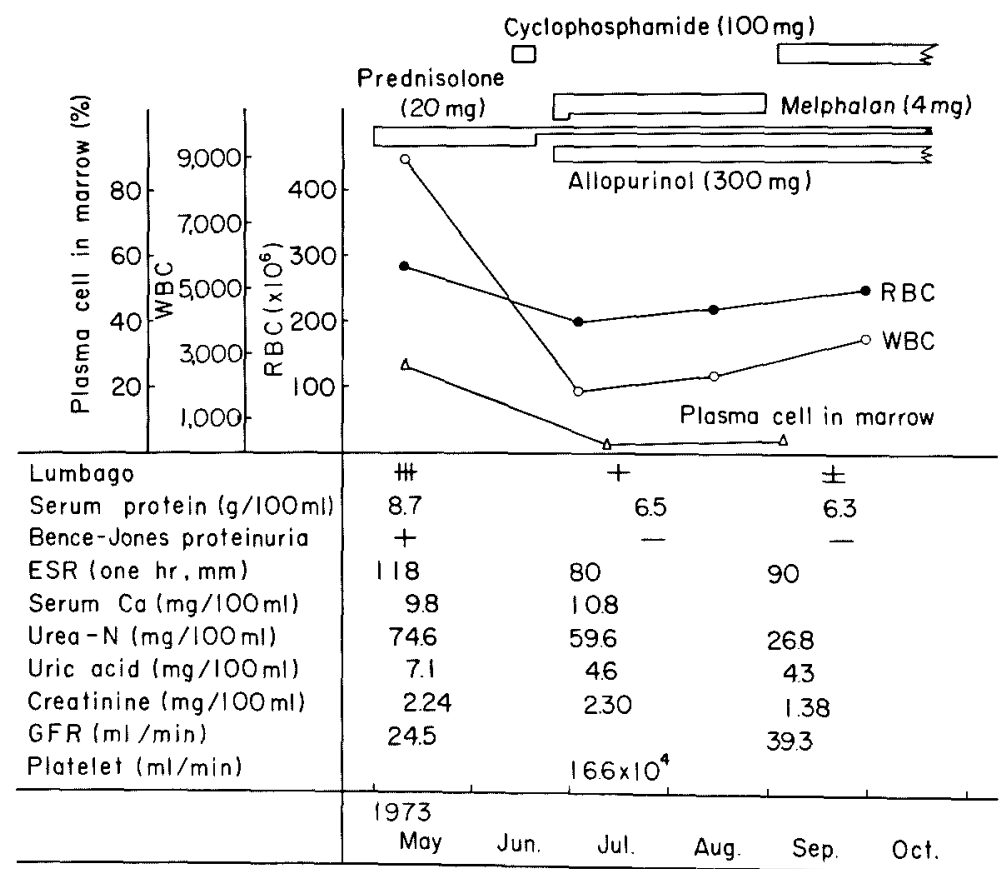

Fig. 6. Part of clinical course of Case 13. 
Fig. 4 represents the similar survival curve of our 6 cases of macroglobulinemia Waldenström. As shown in Table 1, various agents such as corticosteroids, cyclophosphamide, chlorambucil and vinblastine were used. Since the histological features of macroglobulinemia Waldenström are of considerable variety, ranging from chronic lymphyocytic leukemia to reticulosarcoma (Waldenström 1944; Dutcher and Fahey 1959; McCallister et al. 1967; Welton et al. 1968; Ward et al. 1971), appropriate agents should be selected. In case of hyperviscosity syndrome plasmapheresis should be performed (Fahey et al. 1965).

Figs. 5 and 6 represent the clinical courses at the time of admission of two patients with multiple myeloma who are still living 44 months after admission and now being followed in our outpatient clinic. Both of these cases had compression fracture of the lumbar spine and punched-out lesions in the skull. In addition, massive proteinuria (mainly Bence-Jones protein), hypercalcemia, azotemia and hyperuricemia were present as seen in Figs. 5 and 6 . For these metabolic abnormalities appropriate measures were taken as shown in the figures.

\section{DISCUSSION}

The present study was undertaken with the consideration that the detailed follow-up of patients admitted to our institution may clarify whether progress is being made in treatment of multiple myeloma and related diseases. Precise evaluation of the therapeutic response of patients with a multifaceted, chronic disease such as multiple myeloma and macroglobulinemia Waldenström is difficult (Alexanian et al. 1969). Not only chemotherapeutic agents such as cyclophosphamide and melphalan but also improvement in supportive care may be responsible for prolongation of survival. The wider use of serum protein analysis may have detected the illness in earlier phase than in the past.

Nevertheless, it cannot be denied that we see more patients with multiple myeloma receiving treatment on the outpatient basis than in previous years when such patients were never discharged if once admitted. As shown in Fig. 2, since the late 1960s the cases are increasing who can live longer than those in the previous years. It seems most reasonable to ascribe this fact to the appearance of cyclophosphamide and melphalan in this country.

The ultimate results of the effectiveness of treatments may be estimated by the period of survival, as shown in Figs. 3 and 4.50 per cent of our patients with multiple myeloma and with macroglobulinemia Waldenström lived for 18 months and 25 months, respectively. 50 per cent survival of 18 months for multiple myeloma can be regarded as considerably long, since a similar study performed in 1962 in Japan showed that 50 per cent survival for multiple myeloma was about 9 months. Our results, however, are never satisfactory when compared to those of Farhangi and Osserman (1973) who stated that 50 per cent of their multiple meyloma patients lived for 53 months.

Regarding the administration of drugs various methods have been reported such as high dose intermittent regimen (Alexanian et al. 1969; George et al. 1972) 
and low does continuous regimen (McArthur et al. 1970). We simply followed the low continuous dose regimen because of simplicity. Furthermore, combination chemotherapy has been proposed for treatment of multiple myeloma (Lee et al. 1975). Certainly this may deserve further trials. We ourselves had the opportunity of adding vinca alkaloids and procarbazine to cyclophosphamide and melphalan as shown in Fig. 1 and are expecting more trials.

With the increase of old-age people in general population the incidence of multiple myeloma may rise, since this disease occurs mostly in age groups more than 50 years old as shown in Table 1. The interest in plasmacytoma lies not only in this prospected increase, but in the fact that it is a tumor capable of producing abnormal immunoglobulins, although it is not completely denied that these abnormal immunoglobulins are antibodies (Metzger 1969). It is a fact, however, that patients of multiple myeloma often need normal immunoglobulins to combat against various infections, since we have lost some patients on account of severe bacterial infections.

\section{Acknowledgment}

We are indebted to Prof. Kaoru Yoshinaga for his kind help for this study.

\section{References}

1) Alexanian, R., Bergsagel, D.E., Migliore, P.J., Vaughn, W.K. \& Howe, C.D. (1968) Melphalan therapy for plasma cell myeloma. Blood, 31, 1-10.

2) Alexanian, R., Haut, A., Khan, A.U., Lane, M., McKelvey, E.M., Migliore, P.J., Stuckey, W.J. \& Wilson, H.E. (1969) Treatment for multiple myeloma. Combination chemotherapy with different melphalan dose regimens. J. Amer. med. Ass., 208, 16801685.

3) Costa, G., Engle, R.L., Schilling, A., Carbone, P., Kochwa, S. \& Glidewell, O. (1973) Melphalan and prednisone: an effective combination for the treatment of multiple myeloma. Amer. J. Med. 54, 589-599.

4) Dutcher, T.F. \& Fahey, J.L. (1959) The histopathology of the macroglobulinemia of Waldenström, J. nat. Cancer Inst., 22, 887-918.

5) Fahey, J.L., Barth, W.F. \& Solomon, A. (1965) Serum hyperviscosity syndrome. J. Amer. med. Ass., 192, 464-467.

6) Farhangi, M. \& Osserman, E.F. (1973) The treatment of multiple imyeloma. Semin. Hemat. 10, 149-161.

7) George, R.P., Poth, J.L., Gordon, D. \& Schrier, S.L. (1972) Multiple myelomaintermittent combination chemotherapy compared to continuous therapy. Cancer, 29, 1665-1670.

8) Holland, J.F., Hosley, H., Scharlau, C., Carbone, P.P., Frei, E., III, Brindley, C.O., Hall, T.C., Sehnider, B.I., Gold, G.L., Lasagana, L., Owens, A.H., Jr. \& Miller, S.P. (1966) A controlled trial of urethane treatment in multiple myeloma. Blood, 27, $328-342$.

9) Lee, B.J., Sahakian, G., Clarkson, B.D. \& Krakoff, I.H. (1974) Combination chemotherapy of multiple myeloma with Alkeran, Cytoxan, Vincristine, Prednisone, and BCNU. Cancer, 33, 533-538.

10) Mancini, G., Carbonara, A.O. \& Heremans, J.F. (1965) Immunochemical quantitation of antigens by single radial immunodiffusion. Immunochemistry, 2, 235-254.

II) McArthur, J.R., Athens, J.W., Wintrobe, M.M. \& Cartwright, G.E. (1970) Melphalan and myeloma. Experience with a low-dose continuous regimen. Ann. intern. Med., 72, 665-670. 
12) McCallister, B.D., Bayrd, E.D., Harrison, E.G., Jr. \& McGuckin, W.F. (1967) Primary macroglobulinemia. Review with a report on thirty-one cases and notes on the value of continuous chlorambucil therapy. Amer. J. Med., 43, 394-434.

13) Metzger, H. (1969) Myeloma proteins and antibodies. Amer. J. Med., 47, 837-844.

14) Onodera, S., Shibata, A., Miura, A.B., Suzuki, A. \& Sakamoto, S. (1967) Quantitative determination of immunoglobulins as a diagnostic tool for paraproteinemia. Tohoku J. exp. Med., 91, 85-93.

15) Waldenström, J. (1944) Incipient myelomatosis or "essential" hyperglobulinemia with fibrinogenopenia - a new syndrome ? Acta med. scand., 117, 216-247.

16) Ward, A.M., Shortland, J.R. \& Darke, C.S. (1971) Lymphosarcoma of the lung with monoclonal (IgM) gammopathy. Cancer, 27, 1009-1028.

17) Welton, J., Walker, S.R., Sharp, G.C., Herzenberg, L.A., Wistor, R., Jr. \& Creger, W.P. (1968) Macroglobulinemia with bone destruction. Amer. J. Med., 44, 280-288.

18) Wright, D.J. \& Jenkins, D.E. (1970) Simplified method for estimation of serum and plasma viscosity in multiple myeloma and related disorders. Blood, 36, 516-522. 